\title{
Investigação na Formação Inicial: concepções sobre as TIC e a Energia no Curso de Licenciatura em Ciências da Natureza
}

\section{Research in Initial Formation: conceptions about TIC and Energy in the Degree in Science of Nature}

\author{
Ticiane da Rosa Osório (ticiani_dp@hotmail.com) \\ Universidade Federal do Pampa (UNIPAMPA) \\ Vitor Garcia Stoll (vitorgarciastoll@ gmail.com) \\ Universidade Federal do Pampa (UNIPAMPA) \\ Marcio Marques Martins (marsjomm@gmail.com) \\ Universidade Federal do Pampa (UNIPAMPA)
}

Resumo: Este artigo apresenta o recorte de uma oficina desenvolvida no Programa de Pós-Graduação Mestrado Acadêmico em Ensino, vinculado à Universidade Federal do Pampa, Campus - Bagé. O público-alvo foram 19 acadêmicos do quarto semestre de um Curso de Licenciatura de Ciências da Natureza. Objetivou-se entender as concepções destes em relação às TIC e o tema Energia. A pesquisa caracterizou-se como qualitativa, utilizou um questionário como instrumento para coleta de dados, analisado com base na Análise de Conteúdo. Resultados revelaram que grande parte dos acadêmicos relacionou as TIC a tecnologias digitais. Mencionaram também que o uso das TIC pode tornar as aulas mais atrativas e facilitar a compreensão de conteúdos complexos. A Energia foi definida por $90 \%$ como a "capacidade de realizar um trabalho", demonstrando uma concepção simplista do conceito. No que tange a aplicação das TIC e Energia, citaram que utilizariam em suas aulas por meio de pesquisas, simuladores e experimentação. Por fim, considera-se relevante a realização deste trabalho, pois pode contribuir na formação dos licenciandos e em suas práticas enquanto futuros professores.

Palavras-chave: Energia; Formação de Professores; Tecnologias.

Abstract: This article presents a workshop developed in the Postgraduate Program in Academic Master's Degree in Teaching, linked to the Federal University of Pampa, Campus - Bagé. The target audience was 19 fourth-semester academics from a Bachelor's Degree in Natural Sciences. The objective was to understand the conceptions of these in relation to ICT and the Energy theme. The research was characterized as qualitative, used a questionnaire as instrument for data collection, analyzed based on Content Analysis. Results revealed that most academics have linked ICT to digital technologies. They also mentioned that the use of ICT can make classes more attractive and facilitate the understanding of complex content. Energy was defined by $90 \%$ as the "ability to perform work", demonstrating a simplistic conception of the concept. Regarding the application of ICT and Energy, they mentioned that they would use their classes through research, simulators and experimentation. Finally, it is considered relevant to carry out this work, since it can contribute to the training of graduates and their practices as future teachers.

Keywords: Energy; Teacher training; Technologies. 


\section{INTRODUÇÃO}

A área do ensino de Ciências da Natureza é permeada por diversas teorias, metodologias, recursos e ferramentas que buscam facilitar o processo de construção e apropriação do conhecimento em todos os níveis de ensino. Segundo os Parâmetros Curriculares Nacionais (PCN) o desenvolvimento de tópicos básicos de Ciências da Natureza, quando ocorre de forma descontextualizada e mecanicista, não favorece a aprendizagem dos estudantes (BRASIL, 2002). Diante disso, torna-se necessário o desenvolvimento de conceitos, temas e conteúdos articulados com o cotidiano dos estudantes, pois a aprendizagem e o processo de construção do conhecimento estão interligados.

Nas últimas décadas, o ensino de Ciências passou por diversas reformulações e inserção de novas metodologias com o intuito de proporcionar um ensino mais qualificado e aproximado da realidade dos estudantes. Dentre os novos recursos e ferramentas inseridas nas aulas, atualmente as TIC vêm ganhando cada vez maior espaço dentro de todas as áreas, em especial no contexto de sala de aula. Nas escolas há um forte movimento de investimento em aulas, atividades e metodologias utilizando como recurso pedagógico as Tecnologias de Informação e Comunicação (TIC) na tentativa de facilitar a suplementação das necessidades de formação dos sujeitos sem processo de formação e aproximar a teoria da realidade.

Dentre os diversos significados encontrados na literatura da área, Mendes (2008) define as TIC como um conjunto de recursos tecnológicos que podem proporcionar uma comunicação, automação e diversificação em diversos ramos, abrangendo desde o ensino até as pesquisas científicas. Segundo o autor é possível perceber o avanço das TIC em todas as áreas, sendo inegáveis as inúmeras contribuições por estas trazidas.

No âmbito educacional não seria diferente, já que as TIC podem ser utilizadas para reunir, demonstrar e partilhar informações, aproximando cada vez mais a teoria da prática, em especial em conteúdos e temáticas específicas que possuem um grau elevado de abstração, como a Energia. 
Assim, as TIC podem ser consideradas como tecnologias cognitivas e sociais, pois o social propicia que os sujeitos encontrem ideias e interesses comuns por meio das interações ao falar, ouvir e interagir com os pares. Silva (1999, p. 59) destaca a necessidade do ser humano

[...] da informação como de sociabilidade, poder-se-á mesmo afirmar que a informação é um instrumento ou componente para a promoção da socialização e da sociabilidade, que é o objetivo primordial. Através dos grupos sustentados pelas Redes e Serviços Telemáticos o sujeito tem uma ambiência mista em que se funde a sociabilidade com a informação, com a vantagem de a informação seja mais credível pelo fato de ter origem no círculo de sociabilidades do sujeito.

Apesar de conhecer as facilidades e as contribuições das TIC no ensino, é notório que grande parte das práticas pedagógicas nas escolas ainda se exima da utilização desta ferramenta. Moran (2000) faz menção às dificuldades referentes às mudanças educacionais no sentido da inserção das TIC nas aulas, pois acredita que uma aula apoiada neste recurso deve ser mediada por educadores maduros, curiosos, entusiasmados e abertos que possuam a capacidade de integrá-las naturalmente na elaboração de suas aulas. $\mathrm{O}$ autor ainda ressalta as vantagens trazidas pelas tecnologias de informática como a sistematização de dados, imagens, gráficos, bem como vídeos-aula, entre outros que ofertam diversas informações de forma resumida rápida e atraente.

Além de aplicativos, sites e softwares de simulação, também podem aproximar ainda mais o estudante dos fenômenos abstratos, em especial no que tange a área das Ciências da Natureza. Nesses casos, o papel do professor é mediar e auxiliar na condução das atividades e na interpretação das informações disponibilizadas pelos aplicativos, buscando sempre contextualizá-las a fim de que o sujeito realize as relações com seu cotidiano.

Levando-se em consideração essas premissas, neste artigo apresenta-se um recorte dos resultados obtidos na oficina intitulada "Aplicativo Kahoot: uma ferramenta para o ensino de Ciências da Natureza”. Objetivou-se entender as concepções dos acadêmicos de um Curso de Licenciatura em Ciências da Natureza em relação às TIC e o tema Energia. Esta pesquisa está interligada ao Programa de Pós-Graduação Mestrado em 
Ensino (MAE) da Universidade Federal do Pampa - UNIPAMPA - Campus Bagé, no qual os autores estão vinculados.

A escolha pelo tema Energia justifica-se pela possibilidade do desenvolvimento em diversos contextos, sendo estes formais ou não formais, de aprendizagem e em diferentes níveis de ensino. O grau de abstração dos conceitos atribuídos a Energia são elevados, podendo limitar o entendimento do estudante. O conceito de Energia é considerado por Barbosa e Borges (2006) como um dos mais abstratos e complexos de ser entendido dentro do currículo escolar. Devido a esta complexidade, o estudante em grande parte das vezes interpreta o mesmo de forma inadequada e equivocada confundindo este conceito com outros comumente relacionados à potência, movimento e força. Acredita-se que esta abstração se justifica pela diversidade de representações que a Energia pode ser encontrada, tais como a transferência de calor entre os corpos, no calor emitido por uma chama, na radiação solar, na condução da eletricidade, nos movimentos dos corpos em geral, dentre outros (GASPAR, 2009).

Dessa forma, torna-se essencial o desenvolvimento do tema de forma articulada com as componentes curriculares em especial na Química, Física e Biologia. Relacionado a estes aspectos, os PCN expressam que a Energia

[...] é um exemplo importante de um conceito comum às distintas ciências, instrumento essencial para descrever regularidades da natureza e para aplicações tecnológicas. Na Física, pode ser apresentada em termos do trabalho mecânico necessário para impelir ou para erguer objetos, quando se calcula a energia cinética do movimento de um projétil ou veículo, ou a energia potencial da água numa barragem. [...] A falta de unificação entre os conceitos de energia pode resultar em uma "colcha de retalhos energética", a ser memorizada, das energias mecânica e térmica, luminosa, sonora, química, nuclear e tantos outros adjetivos, alguns pertinentes, outros não. Na Biologia e na Química, as energias não são menos importantes e nem menos variadas em suas designações e, no fundo, se trata da mesma energia da Física. [...] É preciso um esforço consciente dos professores das três disciplinas para que o aluno não tenha de fazer sozinho a tradução dos discursos disciplinares ou, o que é pior, concluir que uma energia não tem nada a ver com a outra. (BRASIL, 2002, p.29).

$\mathrm{Na}$ maioria das vezes, o tema é desenvolvido isoladamente, sem conexões entre as componentes curriculares da área Ciências da Natureza. Este tipo de abordagem não favorece o entendimento correto das aplicações e conceitos relativos à Energia, podendo 
causar certa confusão conceitual, ou ainda os estudantes podem entender que a Energia estudada na Química não é a mesma desenvolvida na Física ou na Biologia.

O lócus da pesquisa descrita neste trabalho foi desenvolvida na UNIPAMPA Campus - Dom Pedrito com os acadêmicos do Curso de Licenciatura em Ciências da Natureza. O município localiza-se na microrregião da Campanha, possui 38.916 habitantes e é o $4^{\circ}$ município em extensão do Rio Grande do Sul, com 5250km² (IBGE, 2010).

O Curso de Ciências da Natureza - Licenciatura é constituído pela formação científica interdisciplinar e profissional, ética e reflexiva, comprometida com o desenvolvimento humano e a sustentabilidade ambiental. Além disso, o Curso tem principal objetivo à formação de professores na área de Ciências da Natureza, ou seja, o mesmo habilita o licenciado ao Ensino de Ciências, Biologia, Física e Química nas séries finais do Ensino Fundamental e Médio (UNIPAMPA, 2017).

\section{METODOLOGIA}

Esta pesquisa caracteriza-se metodologicamente como qualitativa. Gil (2010) argumenta que as pesquisas classificadas como qualitativas são consideradas informais em vistas das pesquisas quantitativas, já que possuem maior flexibilidade na organização. Gil (2010, p. 133) ainda ressalta que

[...] depende de muitos fatores, tais como a natureza dos dados coletados, a extensão da amostra, os instrumentos de pesquisa e os pressupostos teóricos que nortearam a investigação. Assim, define-se essa sistematização envolvendo ampliação, interpretação, aprofundamento, sequenciamento e categorização dos dados (GIL, 2010, p. 133).

Devido tais características, nesse tipo de pesquisa geralmente rompe-se o distanciamento entre pesquisador e pesquisados, permitindo uma análise específica de um contexto ou amostra local, preocupa-se, portanto, em compreender o fenômeno e não apenas quantificar e reproduzir.

A oficina foi desenvolvida em quatro etapas. Na primeira, foi aplicado um questionário contendo três questões abertas: 1) Liste algumas contribuições das TIC na construção do teu conhecimento sobre Ensino de Ciências a partir das tuas vivências 
escolares; 2) Defina Energia diante dos conceitos desenvolvidos no Curso de Licenciatura em Ciências da Natureza nas componentes de Química, Física e Biologia; 3) Como futuro professor de Ciências da Natureza, sistematize dois exemplos de atividades envolvendo a temática Energia atrelada às TIC no contexto de sala de aula.

A finalidade da aplicação deste questionário foi verificar as concepções dos acadêmicos do quarto semestre do Curso de Ciências da Natureza - Licenciatura sobre o tema Energia, bem como investigar quais as contribuições das TIC na construção do conhecimento de Ciências ao decorrer da formação básica de ensino. A turma era composta por 19 acadêmicos (17 mulheres e dois homens) com idades compreendidas entre 18 e 72 anos. Escolheu-se esse semestre como público-alvo, pois, neste momento da graduação, já estudaram Componentes Curriculares de Biologia, Física e Química que abordam a temática Energia.

$\mathrm{Na}$ etapa dois, os acadêmicos foram convidados a jogar o jogo intitulado "Jogo das Capitais" no formato de quiz, desenvolvido por meio do aplicativo Kahoot ${ }^{1}$. O intuito desta etapa foi mostrar o funcionamento do aplicativo, bem como as possibilidades de interação entre os pares. Já na etapa três realizou-se, com auxílio de recurso multimídia e slides informativos, a explicação da interface do aplicativo, funcionamento, funções, tipos de jogos e o passo a passo para construção do mesmo.

Na quarta etapa, pós-capacitação, os acadêmicos foram separados em quatro grupos. O intuito desta etapa era de que cada grupo elaborasse um jogo do tipo quiz sobre Energia envolvendo os componentes curriculares da área de Ciências da Natureza (Biologia, Física e Química). Um dos grupos deveria elaborar o jogo de modo interdisciplinar, ou seja, a proposta deveria conter questões referentes aos três componentes curriculares. Neste trabalho, apresenta-se somente a análise dos dados relativos à primeira etapa da oficina.

A análise dos dados embasou-se na Análise de Conteúdo descrita por Bardin (1977), que consiste em três etapas distintas: (I) pré-análise, (II) exploração do material e (III) tratamento dos resultados. 
Na etapa inicial, pré-análise, organizou-se o material a ser analisado. Realizou-se a leitura flutuante dos questionários respondidos pelos acadêmicos na etapa inicial da oficina e transcreveram-se as respostas para uma planilha no Programa Microsoft Excel.

$\mathrm{Na}$ exploração do material, as respostas foram categorizadas por semelhança. Para tanto, com a finalidade de preservar a identidade dos sujeitos da pesquisa, optou-se por utilizar caracteres alfanuméricos nas análises (P1, P2, P3, ..., P19), sendo a letra "P" correspondente a palavra "participante" e o numeral utilizado para substituir o nome.

Por fim, no tratamento das informações, as respostas foram sintetizadas em quadros, gráficos e nuvens de palavras, fundamentais para interpretação dos resultados.

\section{RESULTADOS E DISCUSSÕES}

A primeira questão "Liste algumas contribuições das TIC na construção do teu conhecimento sobre Ensino de Ciências a partir das tuas vivências escolares", tencionava entender as contribuições das TIC ao longo da vivência escolar básica dos acadêmicos.

A partir da análise das respostas, emergiram duas categorias-chave: "concepção restrita" e "concepção abrangente". Na primeira englobaram-se aqueles que fizeram relação direta com as tecnologias digitais, considerando que as TIC, restringem-se apenas aos aparelhos digitais. E no segundo grupo, aqueles que listaram em suas respostas a importância do uso das TIC como ferramenta para instigar e envolver os estudantes nas atividades em sala de aula.

Como exemplos da primeira categoria destacam-se as menções de (P1/P2/P3/P4). Para (P1) o uso das TIC “[...] permite maior acesso dos alunos ao conhecimento através da tecnologia, aliando o ensino tradicional ao moderno”. Já (P2) destaca que, para ela, “[...] facilitou o entendimento, porque elas ajudam na melhor compreensão do ensino. Muito pouco minhas professoras utilizavam nas aulas o laboratório de informática, mas era interessante quando usavam”. De forma semelhante a $(\mathbf{P 3})$ e $(\mathbf{P 4})$ mencionam “Auxiliou na compreensão do ensino de conteúdos mais 
difíceis. Pra mim as aulas eram mais interessantes quando usava os computadores, poucas vezes as professores nos levavam no laboratório de informática."

Observou-se ainda, que (P2/P3/P4) expressam que os professores utilizavam raramente as TIC em suas aulas. A pesquisa realizada por Behrens (1998) argumenta que os professores ainda mantém certo distanciamento das TIC, mesmo sabendo que as mesmas somam e auxiliam no processo de construção do conhecimento, pois aulas desenvolvidas com o auxílio das TIC ainda é um grande desafio na educação.

Outros acadêmicos apenas enumeraram aplicativos e programas computacionais como facilitadores neste processo, indicativos da concepção restrita. Isto fica evidente nas respostas dos participantes (P5/P6/P8/P14), quando destacam: (P5) “O data show é uma das contribuições que auxiliam na melhoria da transmissão de conteúdo e outra ferramenta muito utilizada é o Moodle”; (P6) “As tecnologias encurtaram a distância entre colegas e professores através de ferramentas e redes sociais como email da turma, drive do Google, grupos de faceboock e whatsapp onde as informações circulam de forma acelerada”; (P8) “[...] pesquisas escolares em sites de busca, videoaulas, aplicativos de estudos”; (P14) “[...] trabalhos com simuladores e experimentos”.

Dentro deste contexto, Murphy (2003) citado por Martinho e Pombo (2009), destaca que as TIC quando interligadas ao ensino de ciências podem ser utilizadas para diversos fins, tais como uma fonte de referência, como uma ferramenta valiosa e também como meio de comunicação, divulgação e exploração. Além disso, Murphy (2003) faz menção das potencialidades de informação e comunicação nas quais as TIC promovem, salientando como exemplo o CD-ROM e a internet, por meio do uso do correio eletrônico, de salas para discussão online, de apresentações em Power Point, imagens digitais e o emprego de simulações.

Já os participantes (P16/ P17/P18), agrupados na segunda categoria, listam em suas respostas a relevância do uso das TIC como ferramenta para instigar e envolver os estudantes nas atividades em sala de aula, conforme excertos: (P16) “[...] despertam mais interesse nos estudantes envolvendo-os mais com o conteúdo aplicado [...] o professor consegue se aproximar mais da realidade do aluno e assim o aluno pode perceber que a "ciência” como algo mais palpável”; (P17) "O uso da TIC torna o processo de 
aprendizagem mais interessante, pois usa novas ferramentas para transmitir o conhecimento”; e (P18) “As TIC são de extrema importância para a construção do conhecimento, lembro-me das aulas de ciências com apenas pesquisas escolares na internet”.

Conforme Aguiar (2008) as interações estabelecidas entre os estudantes e a internet modifica de maneira positiva na forma de expressão tanto na leitura como na escrita, já que o acesso às informações sistematizadas e disponíveis em uma sequência criativa facilitam o entendimento, construção e reconstrução em diversas áreas do conhecimento. As TIC ampliam as percepções, já que proporciona a uma nova leitura do mundo, levando ao sujeito refletir e pensar sobre o próprio pensar e por meio destas reflexões agregar mais conhecimento e informações sobre determinado tema. Assim conforme a autora pode-se entender que as tecnologias digitais emergem no sentido de colaborar com o processo de ensino aprendizagem, rompendo com a forma hierárquica e tradicional imposta em muitas escolas.

Na segunda questão "Defina o tema Energia diante dos conceitos desenvolvidos no Curso de Licenciatura em Ciências da Natureza nas componentes que Química, Física e Biologia", verificou-se que as respostas trazidas pelos acadêmicos estão em grande parte atribuídas à concepção de que "Energia é a capacidade de realizar um trabalho"'(P1/P2/P5/P7/P11/P15/P17), concepção restrita. Este resultado relaciona-se com a conceituação sobre Energia definida por Asimov (1979, p.14) como “[...] a propriedade de um corpo que o capacita a trabalhar". Ainda assim, ressalta que a palavra Energia significa "que contém trabalho". Logo as respostas dos acadêmicos atribuindo Energia com a realização de trabalho podem ser consideradas corretas.

Conforme corrobora Coelho (2014), dentre as definições trazidas pelos livros didáticos, as conceituações mais generalistas e rotineiramente utilizadas são "A Energia não pode ser criada, nem destruída, mas apenas transformada", ou, "Energia é a capacidade de realizar trabalho”. A primeira conceituação apresentada restringe-se apenas aos fenômenos da natureza, já a segunda, citada pelos pesquisados, torna-se insuficiente para atender a complexidade e totalidade do tema, limitando-se ao campo da física. Caso estas duas concepções forem desenvolvidas de forma isolada, o que costuma 
acontecer no contexto da sala de aula poderá direcionar ao entendimento equivocado de que a Energia é vista como uma "substância".

Alguns acadêmicos (P3/P4/P6), citam em seus relatos, de maneira restrita, a relação do tema Energia com as componentes do Curso de Ciências da Natureza, conforme excertos: (P3) "Em ciências Energia é um tema utilizado em todas as componentes de forma ampla”; (P4) “[...] é um tema abordado de forma ampla e variada em todas as componentes do Curso"; e (P6) "Energia é um tema que pode ser abordado em todas as áreas de ciências”. Vale ressaltar também a resposta do (P10) “[...] sem perceber fisicamente, usamos e adquirimos a todos momentos que fizemos algumas ações, envolvendo processos relacionados a física, química e biologia”.

Destaca-se que um dos eixos articuladores do Projeto Pedagógico do Curso de Ciências da Natureza é a interdisciplinaridade (UNIPAMPA, 2018), motivo pelo qual, acredita-se que esses estudantes percebem a Energia em mais de uma Componente Curricular. Contudo, por não citarem exemplos específicos dessas relações, tampouco conceituar a temática, não se pode afirmar que possuem uma compreensão abrangente sobre Energia.

A última questão "Como futuro professor de Ciências da Natureza, sistematize dois exemplos de atividades envolvendo a temática Energia atrelada às TIC no contexto de sala de aula", teve como intuito perceber de que modo os acadêmicos desenvolveriam atividades envolvendo o tema Energia e as TIC em aulas como futuros professores. Esta questão foi analisada por meio do softwareWord It Out $^{2}$. A Figura 1 expõe as respostas dos acadêmicos.

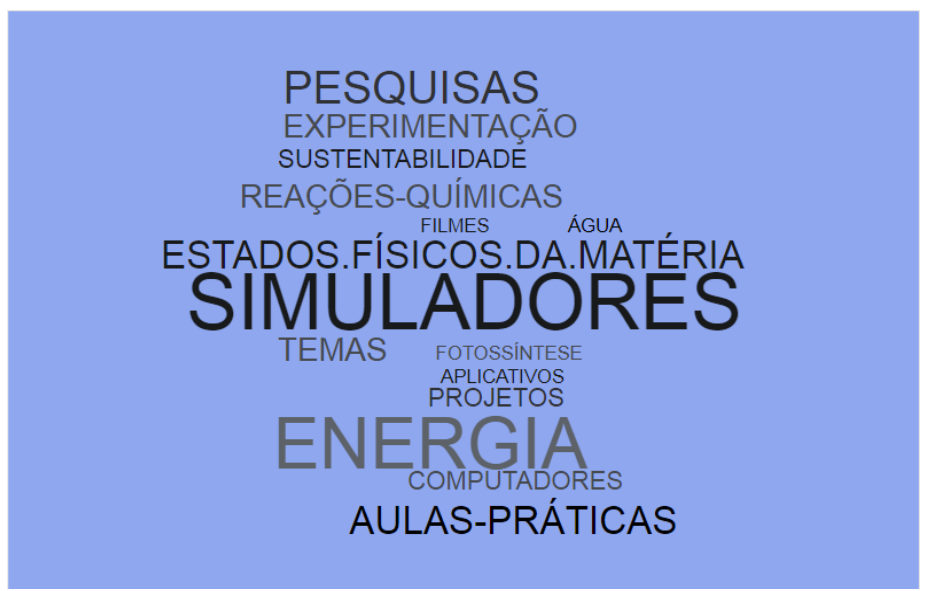


Figura 1: Nuvem de palavras da questão três do questionário. Fonte: Autores (2019)

Analisando a Figura 1 constata-se que as aulas com Simuladores, Pesquisas, Aulas práticas, Experimentação e Computadores foram os recursos mais citados pelos participantes. Além disso, dois dos participantes (P10/P14), mencionaram em suas respostas o desenvolvimento de aulas em espaços não formais de aprendizagem e com instrumentos que não estão diretamente relacionados ao ensino como o uso de filmes e aplicativos interativos de celular. Ao passo que o (P6) relatou " [...] usar projetos seria uma forma de usar a Energia e as TIC para que estudantes percebessem que estas tem ligação [...] assim a Energia elétrica poderia ser estudada mais interessante."

A Energia, Estados físicos da matéria e Reações Químicas foram os conteúdos mais citados. Este fato revela que grande parte dos acadêmicos ainda restringe a atribuição da temática apenas às componentes curriculares de Química e Física. Listaram em suas respostas o desenvolvimento de conteúdos específicos destas Componentes Curriculares como Energia Cinética das Reações Químicas, Estados Físicos da matéria, Circuitos, e alguns tipos de Energia (eólica, hidrelétrica e solar).

Apenas os (P8/P10) expressam à ligação do tema Energia com a Biologia quando destacam (P8) "O conceito de fotossíntese sendo contextualizado com a Energia necessária para os processos da planta [...]”; (P10) “[...] a fotossíntese é um bom conteúdo para trabalhar a Energia [...] através da pesquisa nos computadores perguntando aos alunos como ocorre a fotossíntese."

Frente às respostas salientadas pelos acadêmicos, percebeu-se que alguns apresentam evidências que sinalizam um perfil que ultrapassa a postura disciplinar, revelando traços da formação do Curso de Licenciatura em Ciências da Natureza.

\section{CONSIDERAÇÕES FINAIS}

Dentre os diversos recursos, ferramentas e metodologias disponíveis para o ensino de Ciências da Natureza, as TIC atualmente tomam cada vez maior espaço nas escolas e 
em todos os níveis de ensino. Nesta intervenção inicial percebeu-se a interação entre os pares que se envolveram na atividade proposta. Este fato revela que o processo de aprendizagem deve ser uma construção colaborativa promovendo a troca de saberes. Em relato informal, muitos destes mencionaram que utilizariam o aplicativo posteriormente para realização de propostas relacionadas à Escola e projetos e nos estágios vindouros vinculados a Universidade.

No entanto, percebeu-se nesta pesquisa que grande parte dos acadêmicos, em sua formação básica, tiveram pouco contato com as TIC e as tecnologias digitais nas escolas onde estudaram, mas que mesmo assim reconhecem as contribuições que as mesmas podem trazer ao ensino e aprendizagem.

Na primeira questão verificou-se que a maioria dos acadêmicos entende que as TIC se restringem às tecnologias digitais, já que mencionaram simuladores, computadores, recurso multimídia entre outros. Os mesmos argumentam que as aulas desenvolvidas com o uso das TIC tornam-se mais interessantes e atrativas. Além disso, afirmam que as TIC possibilitam maior compreensão de conteúdos considerados mais difíceis, já que estas proporcionam um ensino mais atualizado.

Na segunda pergunta entendeu-se que $90 \%$ conceituaram corretamente Energia do modo mais clássico, "Capacidade de realizar um trabalho". Apenas $10 \%$ destes não a conceituaram, pois exemplificaram onde a mesma pode ser encontrada ou relataram algumas possibilidades de abordagem.

No que se refere à sistematização de ideias a serem desenvolvidas, investigada na última questão, na prática docente envolvendo a temática Energia e as TIC, notou-se que grande parte dos acadêmicos utilizaria Simuladores como recurso tecnológico, em especial para desenvolver o conteúdo de Energia Cinética e Circuito. Destacaram ainda como exemplo de Plataforma Simuladora, o PhET, que é um projeto de simulações interativas gratuitas de diversas componentes curriculares, vinculada a Universidade de Colorado Boulder.

A experimentação teve boa representatividade nas respostas, já que os acadêmicos consideram que o experimento facilita o entendimento do conceito de Energia, como o 
conteúdo de Reações Químicas, a liberação de Energia para o meio e a quantidade de Energia advinda dos alimentos. As pesquisas individuais ou em grupos com a utilização dos computadores e sites de pesquisas também foram citadas, e estruturadas com perguntas elaboradas sobre o tema.

Considera-se de extrema relevância atividades como a apresentada neste trabalho, já que as TIC estão imersas em nosso contexto de modo significativo e intenso. Logo, a inserção das mesmas nas aulas, em especial na área de Ciências da Natureza, pode ser considerada uma ferramenta valiosa na construção do conhecimento, já que as TIC instigam os sujeitos às atividades propostas, levando o mesmo a ser autor de seu próprio conhecimento. Além disso, aplicativos de fácil acesso como o Kahoot! torna-se alternativas de desenvolver conteúdos por meio de jogos interativos onde os estudantes podem elaborar individualmente ou em grupo saberes referentes ao tema elencado, facilitando assim a construção e reconstrução do conhecimento.

Por fim, verificou-se que as TIC devem funcionar nos âmbitos escolares como facilitadora no processo de elaboração de saberes, já que oferta grandes possibilidades e desafios cognitivos e sociais de estudantes e professores pertencentes a todos os níveis de ensino, podendo ser inseridas nas aulas desde os anos iniciais do ensino fundamental, até o nível superior.

Cabe a cada profissional em educação perceber de que forma tornar as TIC como uma aliada, pois grande parte dos professores utilizam os computadores e a internet restrita a um banco vasto de informações. A não exploração de outras vertentes limita a coloração que as TIC e Internet podem oferecer.

No entanto, faz-se necessário ressaltar que as TIC não podem ser consideradas como a salvação para a educação e que com a sua efetivação nas escolas seria a solução de todas as problemáticas em torno do ensino. Pelo contrário. Ao longo deste trabalho foram enumeradas diversas contribuições que este recurso pode ofertar, mas para que as TIC sejam integradas de modo colaborativo na área educacional, é necessário que os educadores desprendam-se dos receios e pré-conceitos e aos poucos de forma natural e não imposta, integrá-las no contexto de sala de aula de forma facilitada, segura e clara das potencialidades que estas proporcionam no ensino. A forma correta do uso das TIC 
nas aulas, valorizando os estudantes, levando em consideração seus saberes prévios, atrelado a uma pedagogia bem estruturada, somam na aprendizagem significativa dos estudantes. Este trabalho tem apoio financeiro da FAPERGS/CAPES.

\section{REFERÊNCIAS}

AMEM, B. M. V.; NUNES, L. C. Tecnologias de Informação e Comunicação: Contribuições para o Processo Interdisciplinar no Ensino Superior. REVISTA BRASILEIRA DE EDUCAÇÃO MÉDICA. 30 (3): 171 - 180; 2006.

ASIMOV, I. Escolha a sua catástrofe. Círculo do Livro. 1979.

BARBOSA, J. P. V; BORGES, A. T. O entendimento dos estudantes sobre energia no início do ensino médio. Cad. Bras. Ens. Fís. v. 23, n. 2: p. 182-217, 2006.

BEHRENS, M. A. A formação pedagógica e os desafios do mundo moderno. In: MASETTO, M. T. Docência na universidade. Campinas: Papirus, 1998. p. 57-68.

BARDIN, L. Análise de conteúdo. Lisboa: Edições 70, 1977.

BRASIL. Ciências da Natureza, Matemática e suas Tecnologias. Parâmetros Curriculares Nacionais - Ensino Médio: Orientações Educacionais Complementares aos parâmetros Curriculares Nacionais.Brasília: MEC/SEMTEC, 2002.

COELHO, R. L. On the Concept of Energy: Eclecticism and Rationality. Science \& Education. v. 23, n.6, p. 1361-1380, 2014.

COELHO, H. Tecnologias de informação. Lisboa: D. Quixote, 1986.

GASPAR, A. Experiências de Ciências. São Paulo: Ed. Ática, 2009.

MARTINHO, T.; POMBO, L. Potencialidades das TIC no ensino das Ciências Naturais - um estudo de caso. Revista Electrónica de Enseñanza de las Ciencias. v. 8, n. 2, p. 527-538, 2009.

MENDES, A. TIC - Muita gente está comentando, mas você sabe o que é? Portal iMaster, mar. 2008.

MORAN, José Manuel. Contribuições para uma pedagogia de educação online. In: SILVA, Marco. Educação online: teorias, práticas, legislação, formação corporativa. São Paulo: Loyola, p. 39-50, 2003. 
UNIPAMPA. PROJETO PEDAGÓGICO DE CURSO, CURSO DE LICENCIATURA EM CIÊNCIAS DA NATUREZA. Disponível em:<

http://dspace.unipampa.edu.br/bitstream/riu/110/1/PPC_Ci\%C3\%AAncias\%20da\%20N atureza_Dom\%20Pedrito.pdf> Acesso em: 8 de jun. de 2018.

SILVA, L. Globalização das redes de comunicação: Uma reflexão sobre as implicações cognitivas e sociais. In J. A. Alves, P. Campos, \& P. Q. Brito (eds.), O futuro da Internet, p. 53-63, Matosinhos, Centro Atlântico, 1999. 